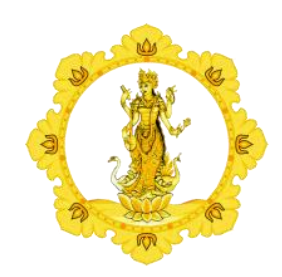

KALANGWAN

JURNAL PENDIDIKAN AGAMA, BAHASA DAN SASTRA

Vol. 9 No. 2 September 2019

\begin{tabular}{|l|l|l|}
\hline p-ISSN : 1979-634X & e-ISSN : 2686-0252 & http://ejournal.ihdn.ac.id/index.php/Kalangwan
\end{tabular}

\title{
ESENSI KEHIDUPAN MANUSIA DALAM TEKS GEGURITAN AJI SESANA
}

\author{
Oleh : \\ I Kadek Widiantana \\ Institut Hindu Dharma Negeri Denpasar \\ E-mail: widiantana@ihdn.ac.id
}

Diterima 07 Juli 2019, direvisi 05 Agustus 2019, diterbitkan 2 September 2019

\begin{abstract}
Lack of knowledge of the nature of life, especially being human, impacts many experiencing stress symptoms, even at the rise of suicides cases. Therefore, it is important to understand the essence of being born human, so that you can live your life as well as possible. One of the Geguritan texts that contains the essence of life being human is the Geguritan Aji Sesana which is considered to be lacking in attention. Therefore, the author uses this Geguritan as a study material, because in the Geguritan summarized the teachings of Hinduism, mainly related to the essence of being born into a human, so that there is no regret to be human. Based on the explanation above, in this paper will discuss about:1) Structure of the Geguritan Aji Sesana; and 2) The essence of human life in the Geguritan Aji Sesana. In analyzing the Geguritan Aji Sesana text, the author uses structural and semiotic theories.

The Geguritan Aji Sesana is a text that contains the essence of being born human, how humans must always cling to the teachings of Dharma, with the essence of being born the main human being. Humans are reminded to always be vigilant with enemies that are in themselves because the enemy is actually inside. Humans are required to always improve themselves by diligently studying literature. But in studying the literature, it must be gradual and begin from the basic level.
\end{abstract}

Keywords: Esensi Kehidupan, Geguritan, Aji Sesana

\section{PENDAHULUAN}

Kesusastraan pengungkapan pikiran yang imajinatif sebagai cermin dari kehidupan manusia dan masyarakat, yang dituangkan melalui bahasa yang indah. Selain itu, kesusasteraan juga 
mempunyai nilai positif terhadap kehidupan manusia. Secara garis besar, kesusastraan Bali dibedakan menjadi dua, yaitu : kesusastraan Bali purwa dan kesusastraan Bali anyar. Salah satu bagian dari kesusastraan Bali purwa adalah geguritan.

Geguritan merupakan salah satu jenis karya sastra yang dihasilkan oleh pengawi pada zaman / masa kerajaan Gelgel. Geguritan sebagai karya sastra lama mengandung nilai-nilai sebagai warisan budaya. Karya sastra yang berupa geguritan mendapat perhatian yang baik dari masyarakat pendukungnya (masyarakat Bali), karena sering dikaitkan dengan seni pementasan seperti : arja, drama gong dan lain sebagainya. Beberapa diantaranya yang populer adalah Geguritan Tamtam, Geguritan Sampik Ingtai, Geguritan Jaya Prana, Geguritan Salya, Geguritan Pakang Raras, Geguritan Durma, Geguritan Putra Sasana dan lain-lainnya. Kesusastraan-kesusastraan tersebut sudah sangat jarang yang menggemari apalagi generasi muda. Animo mereka sangat kurang, apalagi jika yang termuat dalam bentuk lontar dengan teks dan bahasa/aksara yang jauh dari perkembangan zaman, pengetahuan, dan hobby mereka. Oleh karenanya menggali nilai-nilai keagamaan yang tertimbun oleh perkembangan zaman dalam bentuk teks tersebut sangat penting dilakukan.

Kurangnya pengetahuan akan hakekat kehidupan, utamanya menjadi manusia, mengakibatkan banyak yang mengalami gejala stres bahkan sampai pada maraknya kasus bunuh diri. Oleh karenanya, penting kiranya untuk memahami hakekat terlahir menjadi manusia, sehingga bisa menjalani kehidupan dengan sebaik-baiknya.

Salah satu teks geguritan yang memuat tentang hakekat kehidupan menjadi manusia adalah Geguritan Aji Sesana yang dirasa kurang mendapat perhatian. Oleh karenanya, penulis menganggkat geguritan ini sebagai bahan kajian, karena dalam geguritan ini terangkum ajaran-ajaran agama Hindu, utamanya berkaitan dengan esensi terlahir menjadi manusia, sehingga tidak ada penyesalan menjadi manusia. Berdasarkan pemaparan latar belakang di atas, maka dalam tulisan ini akan dibahas tentang: 1) Struktur Geguritan Aji Sesana; dan 2) Esensi kehidupan manusia dalam Geguritan Aji Sesana.

Berkaitan dengan permasalahan tersebut di atas, penulis menggunakan teori struktural untuk menganalisis unsur-unsur pembentuk karya sastra (Geguritan Aji Sesana) dalam kaitannya dengan unsur-unsur lainnya maupun dalam kerangka keseluruhan dari karya sastra tersebut. Secara etimologi, struktur berasal dari kata structura, bahasa latin, yang berarti bentuk atau bangunan. Pendekatan sastra yang mendasarkan pada telaah struktur boleh disebut sebagai pendekatan yang paling banyak menghasilkan teori. Pendekatan struktur itu sendiri sebenarnya sejak jaman Yunani sudah dikenal oleh Aristoteles dengan konsep wholeness (kesatuan), unity (keseluruhan), complexity (kebulatan), dan coherence (keterjalinan) (Teeuw, 1988: 121-134).

Unsur-unsur pembangun struktur tersebut terdiri atas tema, fakta cerita, dan sarana cerita. Tema adalah makna sebuah cerita yang harus menerangkan sebagian besar unsurnya dengan cara sederhana. Fakta cerita adalah suatu struktur faktual yang terdapat dalam sebuah cerita. Fakta cerita terdiri atas alur, tokoh, dan latar. Sarana sastra adalah teknik yang dipergunakan oleh pengarang untuk memilih dan menyusun detail-detail cerita (peristiwa dan kejadian) menjadi pola yang bermakna. Sastra biasanya terdiri atas sudut pandang, gaya bahasa, dan suasana. Simbolsimbol imajinasi dan cara-cara pemilihan judul dalam karya sastra (Stanton, 2007: 12).

Selain teori struktural, juga menggunakan teori semiotik. Istilah semiotik (semiotics) dan semiologi (semiology) sampai kini masih dipakai. Selain istilah semiotika dan semiologi, dalam sejarah linguistik ada pula digunakan istilah lain seperti semasiologi, sememik, dan semik untuk merujuk pada bidang studi yang mempelajari makna dari suatu tanda atau lambang (Sobur, 2003:11).

\section{PEMBAHASAN.}




\section{A. Gambaran Umum Teks Geguritan Aji Sesana}

Bahasa merupakan sesuatu yang paling penting dalam sebuah karya sastra. Sebagaimana telah disebutkan sebelumnya bahwa geguritan adalah sebuah karya sastra tradisional yang mempunyai sistem konvensi sastra yang cukup ketat yang dibentuk oleh sejumlah pupuh. Pupuh-pupuh tersebut diikat oleh beberapa syarat yang disebut padalingsa. Padalingsa yaitu banyaknya baris dan bunyi akhir dalam tiap-tiap baris (Agastia, $1994: 8$ ). Terpenuhinya konvensi tersebut, memungkinkan suatu pupuh ditembangkan sehingga membentuk irama yang menimbulkan rasa estetik. Jenis-jenis pupuh yang membangun Geguritan Aji Sesana antara lain : Pupuh Sinom, Pupuh Pucung, Pupuh Durma, Pupuh Pangkur, Pupuh Dangdang, Pupuh Ginanti dan Pupuh Demung. Geguritan Aji Sesana terdiri dari seratus empat lima (145) pupuh, dan pada bagian akhir ditutup dengan kolofon teks, yang menjabarkan tentang tanggal penyalinan lontar dan asal babon lontar tersebut. Geguritan Aji Sesana digubah dengan menggunakan bahasa Bali yang di tambah dengan kosa kata bahasa Jawa Kuno.

Menurut Agastya (1994 : 3), geguritan merupakan karya sastra tradisional Bali yang mempunyai syarat-syarat penulisan yang cukup ketat. Suatu geguritan yang terbentuk oleh tembang atau pupuh dan biasanya suatu geguritan terdiri dari beberapa tembang atau pupuh. Aji dalam kamus bahasa jawa kuna artinya kitab suci ; teks suci ; teks yang berwenang (Zoetmuleder, 2011 : 17), dan sasana (Skt) memiliki arti perintah, ajaran, doktrin, disiplin, aturan, kumpulan undangundang (Zoetmulder, 2011 : 1050). Jadi Geguritan Aji Sesana merupakan karya sastra yang terikat oleh padalingsa yang memuat tentang pengetahuan akan ajaran ataupun aturan.

\section{B. Struktur Naratif Geguritan Aji Sesana}

Suatu karya sastra merupakan sebuah kesatuan utuh yang dibangun oleh beberapa bagian. Menurut Sukada (1987:88), tema tidak lain daripada ide pokok, ide sentral, atau ide dasar yang bertindak sebagai titik tolak pengarang dalam penyusunan sebuah cerita. Tema juga dapat diartikan sebagai gagasan utama atau ide pokok yang membangun sebuah karya sastra. Adapun tema dalam Geguritan Aji Sesana adalah tentang esensi terlahir menjadi manusia. Hal tersebut dapat dilihat dalam kutipan teks geguritan berikut:

Utama wantah kaucap, mentik kamanusan jani, wireh $i$ manusa siddha, nulung sengsarane sami, ring raga deweke pitui, masasarana ban solah ayu, keto patut $i$ manusa, yan saja pacang ngardinin, nene ayu, ento butitit tekekang (Aji Sesana Lp : 2a).

Terjemahannya :

Disebut utamalah dia, terlahir menjadi manusia, karena manusia bisa menolong dirinya dari kesengsaranya, dengan melaksanakan perbuatan yang baik. Begitulah kepatutan menjadi manusia, jika memang benar akan menjalankan kebenaran. Perbuatan yang baik itu patut dipegang teguh $(A j i$ Sesana $L p: 2 a$ ).

Membaca sebuah karya sastra, biasanya, kita akan dihadapkan pada sejumlah tokoh yang di hadirkan di dalamnya. Namun, dalam kaitannya dengan keseluruhan cerita, peranan masing-masing tokoh tersebut tidak sama. Berkaitan dengan teks Geguritan Aji Sesana, yang menjadi tokoh utama adalah sosok seorang ayah (bapa) dan juga anak (cening). Namun berkaitan dengan tokoh bapa dan cening, bisa saja memiliki makna konotatif, karena bisa mengacu pada percakapan seorang guru dengan muridnya. Jadi dalam kaitannya dengan teks Geguritan Aji Sesana, tokoh yang dimaksud bisa mengacu pada percakapan antara ayah dengan anaknya, ataupun antara guru dengan muridnya.

Suyitno, (2009:49) menyatakan bahwa alur ialah sambung sinambungnya peristiwa berdasarkan sebab akibat. Alur bukan hanya mengemukakan apa yang terjadi, melainkan juga menunjukkan mengapa hal itu terjadi. 
Karena di dalam alur memiliki bagian-bagian yang secara sederhana dapat dilihat sebagai permulaan, pertikaian, perumitan, puncak, peleraian dan akhir. Sedangkan Nurgiyantoro (2010 : 110) menyatakan bahwa alur merupakan kejelasan tentang kaitan peristiwa yang dikisahkan secara linier, akan mempermudah pemahaman kita terhadap cerita yang ditampilkan, kejelasan alur dapat berati kejelasan cerita, kesederhanaan alur berarti kemudahan cerita untuk dimengerti. Adapun alur yang digunakan dalam Geguritan Aji Sesana adalah dengan teknik alur lurus. Berkaitan dengan amanat cerita, Sudjiman (1986:5) menyatakan bahwa amanat adalah gagasan yang mendasari karya sastra, pesan yang ingin disampaikan pengarang kepada pembaca atau pendengar. Amanat yang terkandung dalam teks Geguritan Aji Sesana adalah terlahir mejadi manusia agar selalu berpegang pada dharma.

\section{a. Esensi Kehidupan Menjadi Manusia Dalam Teks Geguritan Aji Sesana}

Kelahiran menjadi manusia merupakan kelahiran yang utama, karena hanya manusia yang dilengkapi dengan sabda, bayu dan idep. Namun dalam kesempurnaan yang dimilikinya, seiring perkembangan jaman, semakin banyak pula tuntutan, tantangan serta godaan yang mesti dihadapi, yang bisa menggoyahkan pikirannya untuk berbuat yang tidak sesuai dengan ajaran agama. Oleh karenanya, penguatan-penguatan akan ajaran agama yang memuat tentang esensi menjadi manusia sangat penting untuk dipahami.

Sesuai dengan judul tulisan ini yang mengangkat Geguritan Aji Sesana, geguritan ini mengisaratkan bagaimana manusia bertingkah laku, dalam bait-bait Geguritan Aji Sesana terlihat bahwa pengawi menekankan akan hakekat terlahir menjadi manusia yang tertuang dalam bait-bait pupuh yang membangun teks Geguritan Aji Sesana. Seperti pada pupuh sinom bait ke-3:

Utama wantah kaucap, mentik kemanusan jani, wireh $i$ manusa sidha, nulung sengsarane sami, ring raga deweke pitui, masarana ban solah ayu, ketot patut $i$ manusa, yan saja pacang ngardini, nene ayu, ento butitit tekekang (Aji Sesana, lp : 2a).

Terjemahannya :

Utamalah disebut, terlahir menjadi manusia, karena manusia yang bisa, menolong dirinya dari kesengsaraan, dalam dirinya sendiri, dengan sarana perilaku yang baik. Begitulah kepatutan menjadi manusia, jika memang benar akan menjalakan kewajibanya, yang baik itu patut dipegang teguh. (Aji Sesana, lp : 2a).

Dalam penggalan pupuh sinom di atas, kelahiran menjadi manusia merupakan sangat utama, yang membedakannya dengan makhluk ciptaan Tuhan yang lainnya. Dengan berbekal idepnya, manusia bisa menentukan kehidupannya kelak, mengingat manusia berbekal karma. Manusia diingatkan untuk selalu memegang teguh solah ayu (perbuatan baik). Bait dari pupuh ini sejalan dengan isi dari kitab sarasamuscaya sloka 4.

Apan ikang dadi wwang, uttama juga ya, nimittaning mangkana, wenang ya tumulung awaknya sangkeng sangsara, makasadhanang subhakarma, hinganing kottamaning dadi wwang ika (Penyusun, $2001: 6)$.

Terjemahannya:

Menjelma menjadi manusia itu adalah sungguh-sungguh utama, yang menyebabkan adalah karena dia dapat menolong dirinya sendiri dari sengsara (siklus suka-duka, hidup-mati berulangulang), dengan perbuatan yang baik, demikianlah keutamaan menjadi manusia (Penyusun, 2001 : 6).

Ketika sudah terlahir menjadi manusia, manusia juga harus selalu mengingat hukum karma, karena tidak ada perbuatan yang tidak 
ada phala (hasil). Hal ini ditekankan dalam pupuh sinom dalam Geguritan Aji Sesana :

Patute dadi manusa, ala ayu kakardinin, gawe ala ayu ento, pacang kaduduk kawingking, yan kala neka kaapti, ditu jani pacang pupu, ento madan pala karma, pagawene nene nguni, sinah tepuk, tuara bisa pacang belas. (Aji Sesana, lp :2b.).

Terjemahannya :

Kepatutan menjadi manusia, baik dan buruk yang diperbuat, prilaku baik dan buruk itu, akan diterima dikemudian hari, jika memang sudah waktunya, disana akan diterima hasilnya, itu yang disebut buah dari perbuatan, prilaku ketika dahulu, pasti akan ditemui hasilnya, tidak akan bisa dilepaskan. (Aji Sesana, lp : 2b.).

Ajaran karmaphala di atas juga dijabarkan kembali dalam teks Geguritan Aji Sesana, sesuai dengan pembagian karma phala, yaitu sancita karmaphala prarabda karmaphala dan kriyamana karma phala, namun dengan bahasa sederhana yang mudah dimengerti, tanpa mengungkapkan istilahistilah dalam pembagian karma phala itu sendiri.

Buin ada dadi janma, tan sah ngagem dharma jati, masih lacure ketama, tong mangruwat papa sakit, ento masih kawastanin, sengkala tingkahe hidup, mula saking pala karma, bekel lacure numitis, eda ngambul, riwekas masih jantosang (Aji Sesana, Lp : 3a).

Terjemahannya :

Ada lagi manusia, yang selalu mengemban ajaran dharma yang utama, namun tetap tertimpa kemalangan, hidupnya selalu ditimpa papa dan sakit, itu juga yang disebut dengan kemalangan hidup, memang asalnya dari buah perbuatan, bekal kelahirannya, jangan putus asa, karena kehidupan selanjutnya juga akan dinanti (Aji Sesana, lp : 3a).

Penggalan di atas mengajarkan ajaran sancita karma phala. Bagaimana karma pada kehidupan sebelumnya, mempengaruhi kehidupan sekarang walaupun pada kehidupan sekarang sudah menjalankan ajaran dharma. Manusia pada hakekatnya ketika terlahir berbekal hasil perbuatan pada kehidupan sebelumnya. Walaupun demikian, manusia diingatkan untuk selalu teguh menjalani hidup, karena apa yang menimpa kehidupan walaupun ditimpa kesengsaraan, tidak bisa lepas dari phala dari perbuatan pada kehidupan sebelumnya.

Dalam penggalan pupuh selanjutnya, diceritakan keberadaan si miskin (tiwas) dan kurus (berag) walaupun tubuhnya sesungguhnya gemuk. Disebut kurus karena tidak bisa melaksanakan swadarmanya. Begitu juga si kaya (sugih), lara hidupnya tidak ada bedanya. Karena dalam dunia ini, ada dua kebenaran, yaitu baik dan buruk (ala wiadin ayu). Salah satunya pasti akan dijalani ketika terlahir menjadi manusia. Karma itu tidak bisa dihindari, dan pengarang menjelaskan dengan pemilihan diksi bahwa karma itu tidak bisa dikasi tahu, dan tidak akan mau pergi. Seperti penggalan pupuh pucung di bawah ini :

Yadin ala yadin ayu, tusing pesan enyak, pacang tuara katepukin, mula pengkung, tuara enyak pacang tinggal. (Aji Sesana, lp : 5a).

Terjemahannya :

Walaupun baik ataupun buruk, tidak akan mau, tidak akan bisa ditemui, karena memang bebal dan tidak akan mau pergi. (Aji Sesana, lp : 5a).

Karmapala juga dikatakan sakti, tidak bisa untuk diubah. (nitah tuduh, tuara dadi ban mangobah). Oleh karenanya, penulis yang mengisatkan dirinya sebagai seorang ayah (bapa), mengharapkan agar anak- 
anaknya mengikuti petunjuk sastra. Sastra ibarat sebagai lampu penerang. Pada pupuh ke-33, yang menggunakan pupuh durma, pengawi mengucapkan secara jelas kutipan sastra yang diambil, menegaskan kembali akan hakekat hidup ini merupakan perjalanan karma.

Kaucapang ring aji sarasamuscaya, $i$ dharma anggen murwanin, pinaka tatakan, yan tatas ring sila dharma, saluir indriane sami, tuara nyengkala, di awake maka sami. (Aji Sesana, lp:7a).

Terjemahannya :

Diucapkan dalam kitab sarasamuscaya, dharma yang patut selalu diutamakan. Dipergunakan sebagai dasar , jika sungguh mengetahui akan prilaku dharma, samua indria, tidak akan memberikan kesengsaraan pada tubuh kalian semuanya (Aji Sesana, lp:7a).

Geguritan Aji Sesana juga mengungkapkan akan sumber kehidupan manusia yang disebut dengan sabda bayu idep. Bagaimana ajaran Tri Kaya Parisudha harus dijalankan dengan sebaik-baiknya. Selanjutnya, terlahir menjadi manusia diingatkan akan musuh terbesarnya yang letaknya ada dalam diri diri, tidaklah jauh tempatnya. Hal ini dipesankan lewat pupuh selanjutnya :

Kene buin bapa nuturin makejang, indik satru mitra sakti, tuah dini di awak munguh

ring tatwa tatwa, mangraksa tangarin ugi, wireh suba trang, satru mitra bulak balik (Aji Sesana, lp ; 10b-11a)

Terjemahannya :

Dan ayah kembali memberitahu kepada sekalian, tentang musuh yang sungguh-sungguh tiada tandingan, adalah di dalam diri, ada di dalam tatwa-tatwa, itu patut diwaspadai, karena sudah jelas, musuh dan teman keberadaannya silih berganti. (Aji Sesana, lp ; 10b-11a).

Penggalan pupuh di atas, mengisaratkan bahwa musuh terbesar manusia adalah pada dirinya sendiri, tidak jauh letaknya. Selama ini, manusia cenderung menyalahkan orang lain tanpa melihat dirinya sendiri. Dalam penggalan pupuh ini, manusia diajarkan untuk lebih belajar ke dalam, mengetahui akan hakekat dirinya sendiri. Penggalan pupuh ini juga sejalan dengan salah bait kakawin Ramayana sargah I.

Ragadi musuh maparo, ri hati ya tonggwania tan madoh ri awak, yeka tan hana ri sira, prawira wihian sireng niti ( Kakawin Ramayana Sargah I).

Terjemahannya :

Kama (nafsu) keinginan adalah musuh yang dekat dihatilah tempatnya tidak jauh dari badan, itu tidak pada Prabu Dasarata, pemberani dan bijaksana sebagai raja.

( Kakawin

Ramayana Sargah I).

Selain ajaran dia atas, Geguritan Aji Sesana juga mengambil penggalan cerita dari partha yajnya, yang dirangkai menjadi beberapan bait pupuh, menggambarkan bagaimanana petuah dari Sang Dharmawangsa kepada Sang Bima. Di sini ditekankan akan ajaran kelepasan, bagaimana mencari jalan kematian.

Pitutur sang Dharmawangsa, ring sang Bima ngasih asih, duh adi Sang Bhimasena, eda ngamuk nene jani, eda ngulah nagih mati, mati dini kadi suwung, yan tonden ada jalaran, jalarania sane luih, nene patut, bekelang ngungsi antaka (Aji Sesana, lp : 11b). 
Terjemahannya :

Petuah dari sang Dharmawangsa, kepada Sang Bima, wahai Sang Bhimasena, jangan engkau mengamuk seperti ini, jangan mengharapkan datanganya kematian, meninggal itu seperti kesepian, jika tidak ada jalannya, carilah jalan kematian yang baik, dipergunakan bekal menuju kematian (Aji Sesana, lp : 11b).

Pengawi memberikan contoh akan perbuatan baik dan buruk yang semuanya ada hasil /phala, lewat cerita Mahabharata, yang mengisahkan perang saudara antara pandawa dan korawa. Pengawi juga memasukkan pesan dengan mencontohkan kehidupan Sang Rama pada wiracerita Ramayana, utamanya ketika memberikan wejangan kepada Sang Bharata.

Keto sadaging sastra, krana pisaratang cening, selegang ugi melajah, apang nawang tutur jati, tingkahe dini numitis, apang eda pati jlamut, kabisane ngawag-awag, sanghyang sastra ngawe paling, salah surup, yan pelih ban nyusupang. (Aji Sesana, lp:14a.).

\section{Terjemahannya :}

Demikian isi dari sastra, oleh karenanya pahami dengan baik anaku, sehingga mengetahui ajaran yang sesungguhnya, bagaimana ketika lahir, agar tidak sembarangan. Kepintarannya tanpa dasar, pengetahuan itu bisa membuat bingung, salah mengartikan, jika salah dalam mempelajarinya (Geguritan Aji Sesana, lp:14a.)

Penggalan pupuh di atas, mengingatkan agar manusia tidak salah dan tidak sembarangan dalam mempelajari sastra. Karena jika salah menafsirkan sastra tersebut, bisa membawa manusia ke jalan yang salah.
Dalam bait pupuh selanjutnya, pengawi mengibaratkan pengetahuan sebagai pohon beringin, dengan cabang yang begitu banyak, ada akar, pangkal, dan juga daun yang begitu lebat, itu semua patut diketahui dengan baik agar tidak salah menyebutkan. Demikian pengawi mengibaratkannya. Sejalan dengan tersebut, pengawi juga mengambilkan contoh lewah ajaran yang ada dalam wraspati tatwa, yang berisikan petuah dari Sang Hyang Siwa kepada Bhagawan Wraspati. Bagaimana tujuh orang buta, yang meraba bagian tubuh dari gajah. Ada yang meraba bagian perut, ada pada bagian kaki dan bagian tubuh yang lainnya yang tentunya akan menimbulkan penafsiran yang berbeda-beda.

Kna cening matangaram, mangurukin Sang hyang aji, wi tattwa tutur katah, angde kadi punyan bingin, carang liu tur mebangsing, ada akah bongkol muncul, turing edonnyane samah, ento sengka mangingetin, bongkol muncuk, bangkiangnyane engken sambat ( geguritan aji sesana, lp : $14 b)$.

\section{Terjemahan}

Anaku patut waspada, dalam mempelajari sastra, karena ajaran ajaran ketuhanan itu banyak, seperti halnya pohon beringin, rantingnya begitu banyak, ada akar, batang dan ujung, apalagi daunnya lebat, itu patut diingat, pangkal dan ujungnya, begitu juga yang bagian tengah (Geguritan Aji Sesana, lp : 14b).

Petikan pupuh di atas, mengingatkan agar ketika terlahir menjadi manusia harus tekun mempelajari sastra namun tidak sembarangan dalam mempelajarinya. Belajar diingatkan agar diawali dari tingkat dasar (bongkol), jangan melompati prosesnya.

\section{b. Simpulan}

Geguritan Aji Sesana merupakan teks yang sarat akan ajaran bagaimana esensi 
terlahir menjadi manusia. Kelahiran menjadi manusia adalah sungguh utama. Sebagai makhluk yang utama, manusia sepatutnya melaksanakan dan berpegang teguh pada ajaran dharma. Manusia diingatkan untuk selalu waspada dengan musuh yang ada pada dirinya sendiri karena musuh terbesar manusia ada pada dirinya sendiri, bagaimana mengendalikan kama dan indria yang ada dalam diri. Dalam menjalani kehidupan, manusia agar selalu mendalami dan berpegang pada sastra. Namun dalam mempelajari sastra tersebut, harus bertahap dan diawali dari tingkat dasar (bongkol) dan tidak sembarangan dalam mempelajari sastra agama.

Mendalami dan melaksanakan setiap ajaran yang tersirat dalam Geguritan Aji Sesana, merupakan salah satu cara agar manusia bisa memahami akan hakekat kelahirannya sehingga tidak akan ada lagi penyesalan menjadi manusia walaupun terlahir dalam keadaan cacat, miskin ataupun bentuk kesengsaraan lainnya. Bagaimana manusia agar selalu meningkatkan kemampuan dirinya.

\section{DAFTAR PUSTAKA}

\section{A. Alih Aksara Lontar}

Lontar Geguritan Aji Sesana.

\section{B. Buku}

Agastia, Ida Bagus Gede. 1994. Ida Pedanda Made Sidemen: Pengarang Besar Bali Abad ke-20. Denpasar: Wyasa Sanggraha.

Kajeng. 2001. Sarasamuscaya. Denpasar : Pemerintah Provinsi Bali

Nurgiyantoro, Burhan. 2010. Teori Pengkajian Fiksi. Yogyakarta: Gadjah Mada University Press.

Sobur, Alex. 2003. Semiotika Komunikasi. Bandung: PT Remaja Rosdakarya.
Stanton, Robert. 2007. Teori Fiksi Robert Stanton. Pustaka Pelajar: Yogyakarta.

Sudjiman, Panuti. 1986. Kamus Istilah Sastra. Jakarta : PT Gramedia.

Sukada, I Made. 1987. Pembinaan Kritik Sastra Indonesia. Masalah Sistematisasi, Analisis Struktur Fiksi. Bandung: Angkasa.

Suyitno. 2009. Kritik Sastra. Surakarta: Lembaga Pengembangan Pendidikan (LPP).

Teeuw, A. 1988. Sastra dan Ilmu Sastra: Pengantar Teori sastra. Pustaka Jaya: Jakarta

Tim Penyusun. 1986. Kekawin Ramayana. Denpasar : Pemerintah Provinsi Bali.

Zoetmulder. 2011. Kamus Jawa Kuna Indonesia. Jakarta : PT Gramedia Pustaka Utama. 